\title{
Dacriocistite aguda: relato de 2 casos
}

\author{
Acute dacryocystitis: two cases reports
}

Silvia Helena Tavares Lorena', João Amaro Ferrari Silva²

\section{ResUmo}

A obstrução da via lacrimal no adulto pode ser congênita ou adquirida. No caso da forma adquirida, a etiologia se classifica em não específicas (o que envolve o epitélio de revestimento e/ou o plexo vascular submucoso do ducto lácrimo-nasal) e específicas (infecções, inflamações, traumatismos, tumores e iatrogenias). O diagnóstico é estabelecido por meio da anamnese, seguida de avaliação clínica baseada na semiologia das vias lacrimais. Os pacientes acometidos pela obstrução da via lacrimal apresentam epífora, dores agudas e tumefação, principalmente na região do saco lacrimal, ocasionando ainda ectasia do mesmo em grau variável, podendo culminar com fistulização cutânea. Ao exame por imagem, utilizamos rotineiramente a dacriocistografia, que representa um ótimo meio de indicar a técnica cirúrgica mais viável. A dacriocistorrinostomia é indicada assim que for tratado o quadro clínico agudo inflamatório.

Descritores: Dacriocistite; Dacriocistorinostomia/métodos; Doenças do aparelho lacrimal/fisiopatologia; Obstrução dos ductos lacrimais/cirurgia; Relatos de casos

'Médica Oftalmologista Colaboradora do Setor de Vias Lacrimais da Universidade Federal de São Paulo - UNIFESP - São Paulo (SP), Brasil;

${ }^{2}$ Chefe do Setor de Vias Lacrimais da Universidade Federal de São Paulo - UNIFESP - São Paulo (SP), Brasil;

Trabalho realizado no Setor de Vias Lacrimais da Universidade Federal de São Paulo - UNIFESP - São Paulo (SP), Brasil.

Recebido para publicação em: 8/2/2010 - Aceito para publicação em 21/9/2010 


\section{INTRODUÇÃO}

A obstrução da via lacrimal no adulto pode ser classificada em duas fases: a primária, que apresenta um infiltrado linfoplasmocitário que vem a culminar com um processo cicatricial; e a secundária, que se caracteriza por apresentar um carcinoma nasofaríngeo e basocelular de canto interno, fraturas mediofaciais, leucemia, sarcoidose, tuberculose, tracoma, Síndrome de Down, Síndrome de Steven-Johnson, leishmaniose, lepra, linfoma, migração de plugs e iatrogenias) $)^{(1)}$.

As manifestações clínicas da obstrução do ducto nasolacrimal cursa com epífora, seguida por processo inflamatório e infeccioso, levando ao quadro de dacriocistite crônica ${ }^{(2)}$

A dacriocistite aguda surge a partir de um processo inflamatório crônico, culminando com a oclusão do canalículo comum, surgindo em consequência um abscesso no interior do saco, apresentando tumoração dolorosa, abaixo do ligamento palpebral medial e celulite orbitária pré-septal nos casos ipsilateral, não ocorrendo refluxo de secreção purulenta. Há casos de expansão para a órbita, causando abscesso intraconal com proptose do bulbo ocular e trombose do seio cavernoso. Os agentes etiológicos mais frequentes desta patologia são: Staphylococcus aureus, Streptococcus betahemolítico, Pneumococcus e Haemophilus influenzae. O diagnóstico é realizado com base nas manifestações clínicas, sendo comum em história pregressa de dacriocistite crônica ${ }^{(23)}$. O tratamento consiste na aplicação de compressas geladas sobre a área inflamada e uso de antibióticos sistêmicos. A dacriocistorrinostomia é necessária após o controle da infecção ${ }^{(3-5)}$.

A dacriocistite é mais frequente nas mulheres, rara na raça negra e apresenta predisposição hereditária ${ }^{(6)}$. Manifesta-se com epífora, às vezes, com conjuntivite crônica ou recorrente, ocasionando edema indolor no canto medial, abaixo do ligamento palpebral medial. Uma vez que a secreção purulenta se acumula no interior do saco lacrimal, ocasiona uma ectasia, apresentando um abaulamento cístico sob a pele. Uma compressão na região do saco lacrimal resulta em refluxo de material purulento para o fórnice. O paciente se queixa de turvação visual, devido ao aumento da espessura do filme lacrimal. Os agentes etiológicos mais frequentes desta patologia são: Staphylococcus aureus e Staphylococcus epidermitis ${ }^{(7,8)}$. Em relação ao tratamento, são recomendadas medidas de higiene, associadas a colírios antissépticos e antibióticos. O tratamento definitivo é o

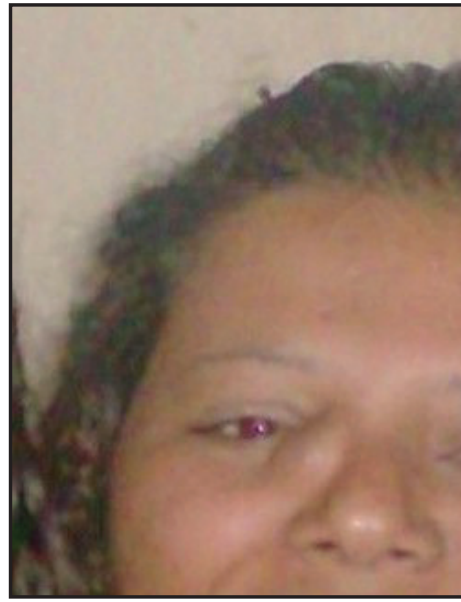

Figura 1: Abaulamento em canto medial do olho direito

cirúrgico (dacriocistorrinostomia externa ou endonasal)

O diagnóstico diferencial da dacriocistite se faz com abscessos cutâneos, etmoidite anterior aguda, dermóides, hemangiomas cavernoso, fibromas, daciolitíase e mucocele de saco lacrimal ${ }^{(8,9)}$.

O objetivo desta apresentação é relatar dois casos de dacriociste aguda, sendo que no primeiro caso ocorreu uma grande ectasia do saco lacrimal e no segundo evoluiu para uma grande fístula cutânea com enorme quantidade de secreção mucopurulenta.

\section{Relato de Casos}

\section{Caso 1}

VST, 26 anos, sexo feminino, parda, natural e procedente de São Paulo, estudante. Apresenta queixa de lacrimejamento em olho direito e abaulamento em canto medial ipsilateral há 1 ano (Figura 1). História pregressa: Iniciou quadro de abaulamento em canto medial do olho direito, quando então procurou o setor de vias lacrimais da UNIFESP, onde foi prescrito Cefaclor $500 \mathrm{mg}$ de $8 / 8 \mathrm{~h}$ por 10 dias, associado com Teflan, 1 comprimido ao dia por 5 dias. Após o procedimento a paciente evoluiu para fístulização cutânea a qual se cicatrizou após 3 meses.

É importante salientar que no ambulatório de vias lacrimais da UNIFESP foram solicitados os exames: ressonância magnética (Figura 2), cujo laudo apontava: formação ovalada no canto ínferomedial da órbita direita, de contornos regulares, medindo cerca de 2,6x2,1 1 1,3 $\mathrm{cm}$ e ultrassom (Figura 3) cujo laudo foi lesão cística extraocular, em canto ínferomedial da órbita direita, medindo no diâmetro horizontal $16,1 \mathrm{~mm}$ e no vertical $22,9 \mathrm{~mm}$, com afinamento da parede óssea do osso 
etmoidal. No dia 24 de julho de 2009 foi submetida à dacriocistorrinostomia sem intercorrências.

\section{Caso 2}

DBCS, 40 anos, feminina, branca, casada, manicure, natural e procedente de Caçulé (Bahia). Queixavase de ulceração em canto medial do olho esquerdo há 2 semanas. Referia lacrimejamento em olho esquerdo há 15 anos e há 10 anos refluxo de secreção purulenta, quando comprimia a região do saco lacrimal esquerdo.

Ao exame apresentava visão igual a 1,0 em ambos os olhos, ausência de proptose ocular, movimento extraocular preservado, hiperemia e edema em canto lateral da órbita esquerda associado com enorme fístula cutânea (Figura 4) ; Teste de Milder:OD:+1;OE:+4 e Refluxo:-OE. Nesta ocasião, foi prescrito: Cefaclor 500mg

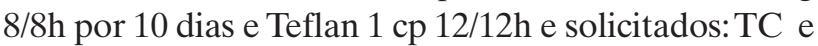
cultura da secreção. O resultado da cultura foi positivo para Staphilococcus aureus e Haemophilus influenzae e a TC de seios paranasais esquerdo, em corte axial, evidenciou espessamento e realce da região pré-septal orbitária. Em 15 dias houve o fechamento da fístula, momento em que foi solicitado uma dacriocistografia, que revelou obstrução da via lacrimal excretora ao nível da válvula de Krause, sendo então, realizada a dacriocistorrinostomia.

\section{DısCUSSÃO}

A primeira crise aguda ocorre após uma dacriocistite crônica ${ }^{(1)}$. A incidência de obstrução da via lacrimal aumenta com a idade. Segundo a literatura, aos 90 anos de idade, cerca de $35 \%$ a $40 \%$ apresentam esta obstrução, uma vez que nesta idade há uma diminuição na produção da lácrima, levando a uma má lubrificação da mucosa do saco lacrimal e do ducto nasolacrimal, ocorrendo descamações e fibrose, culminando com obstrução da via lacrimal excretora ${ }^{(2,3)}$.

As obstruções lacrimais são mais frequentes nas mulheres do que nos homens (10:1). Segundo a literatu$\mathrm{ra}^{(6)}$, isto se explica, devido ao fato de as mulheres apresentarem um canal ósseo do ducto lácrimo-nasal mais angulado, menor e estreito, além do que, na época da menopausa as alterações hormonais levam ao engurgitamento venoso da mucosa do ducto, obstruindo o canal. A raça branca apresenta uma maior incidência de obstrução, devido à conformação óssea do ducto lácrimo-nasal. Verifica-se uma maior frequência de obstrução em camadas mais pobres, em decorrência de precários hábitos higiênicos ${ }^{(8)}$.

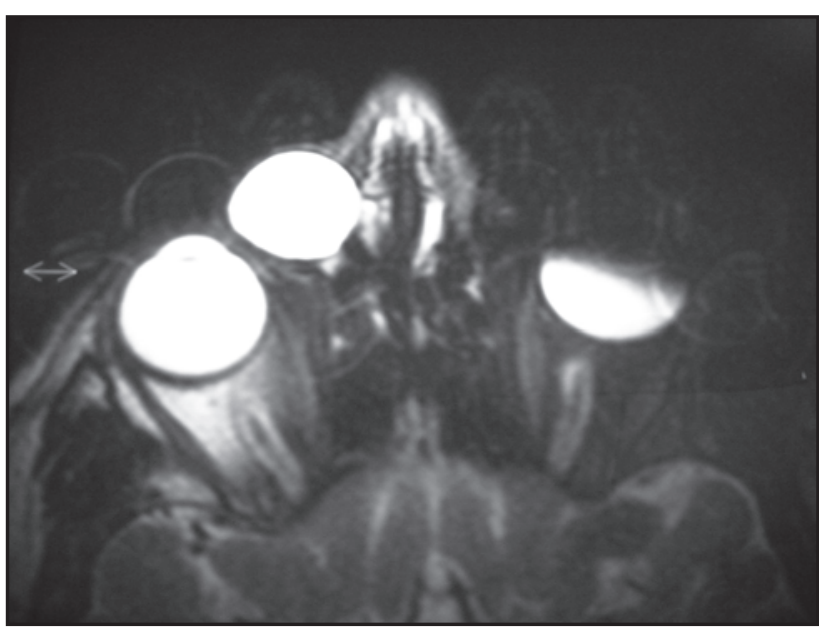

Figura 2: Ressonância magnética: formação ovalada no canto ínferomedial da órbita direita, de contornos regulares, medindo cerca de $2,6 \times 1 \times 1,3 \mathrm{~cm}$

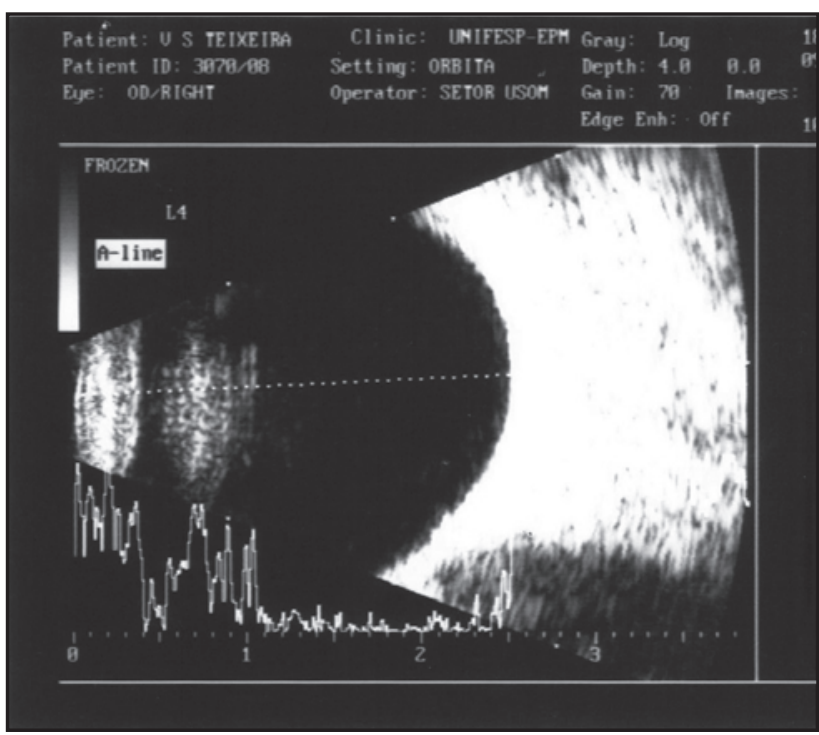

Figura 3: Ultrassonografia ocular: lesão cística extraocular, em canto ínferomedial da órbita direita, medindo no diâmetro horizontal $16,1 \mathrm{~mm}$ e no vertical $22,9 \mathrm{~mm}$, com afinamento da parede óssea do osso etmoidal

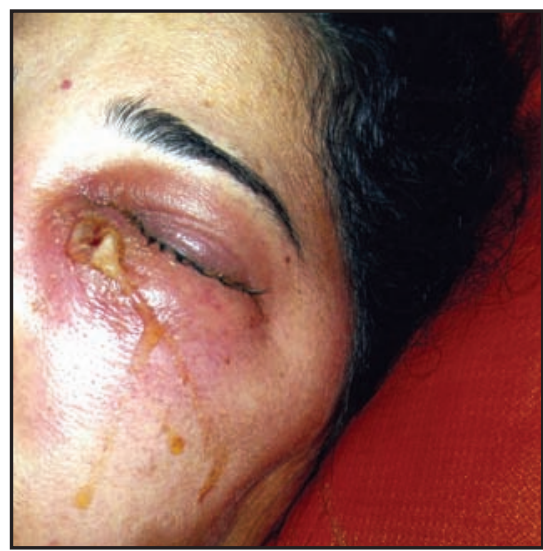

Figura 4: Observase grande fístula cutânea em região medial da órbita esquerda 


\begin{abstract}
The adult lacrimal obstruction can be congenital or acquired. In the case of the acquired form, the etiology classifies in not-specific (it involves the coating epithelium and/or the vascular plexus submucosae of the lacrimal duct) and specific (infections, inflammations, tumours and iatrogenies). The diagnosis is established by means of the anamnesis and clinical evaluation based on semiology of the lacrimal sack. The patients with lacrimal obstruction present epiphora, acute pains and swelling, mostly in the region of the lacrimal sack causing ectasye of various degrees whichn culminate with cutaneous fistulization. The image exams routinely proposed for dacryocystography, which represent a great help in showing the best surgical technique for dacryocystorhinostomy, will be indicated as soon as the acute inflammatory state is treated.

Keywords: Dacryocystitis; Dacryocystorhinostomy/methods; Lacrimal apparatus disease/ physiopathology; Lacrimal duct obstruction/surgery; Ophthalmologic surgical procedures; Case reports
\end{abstract}

\section{REFERÊNCIAS}

1. Coden DJ, Hornblass A, Haas BD. Clinical bacteriology of dacryocystitis in adults. Ophthal Plast Reconstr Surg. 1993;9(2):125-31.

2. Linberg JV. Lacrimal surgery. New York: Churchill Livingstone;1988. Pathology of nasolacrimal duct obstruction. p. 169-200.

3. Volpini M,Couto Jr AS, Costa MN, Caldato R, Martin ZS, Moura EM. Propedêutica .In: Soares EJC, Moura EM, Gonçalves JOR. Cirurgia. São Paulo: Roca; 1997. p.457-77.

4. Levine MR. Dacriocistorrinostomia. In: Levine MR. Manual de cirurgia. Rio de Janeiro: Rio Medi Livros: 1994. p.245-55.

5. Silva JA. Dacriocistorrinostomia 1. Rev Bras Oftalmol. 1988; 47(3):184-5.

6. Genovesi MP, Túlio DH, Macotti , Esteves FF. Patologia del aparato lacrimal. Arch Oftalmol.1987; 62:251-6.

7. Hendrickson DA, Cunningham RK, Veirs ER.. Posttraumatic lacrimal-antral fistula:report of two cases. Ann Ophthalmol. 1977;9(4):457-6.

8. Garfins SW. Etiology of dacryocystitis and epiphora. Arch Ophthalmol 27:167,1942

9. Costa MN, Macchiaverni N. Dacriocistorrinostomia externa. Arq Bras Oftalmol. 1989:52(4):140. 